(C) М.М. Івачевський, 2019

УДК 616.833.34-089.5-031.83:616-073.432.19:615.84

\title{
Аксилярна блокада плечового сплетіння під одночасним контролем ультразвуку та нейростимулятора
}

\author{
М.М. Івачевський \\ email: ivachevskij.m@gmail.com
}

Ужгородський наиіональний університет, медичний факультет, кафедра онкології, Закарпатська обласна клінічна лікарня імені Андрія Новака, Ужгород

\section{Реферат}

Вступ. У статті представлені результати поєднання ультразвукової діагностики та нейростимуляції для проведення аксилярної блокади у пацієнтів, яким проводилися оперативні втручання на верхній кінцівці.

Мета дослідження. Впровадження в клінічну практику аксилярної блокади плечового сплетіння під одночасним контролем ультразвуку та нейростимулятора.

Матеріали та методи. У дослідження було включено 15 пацієнтів, яким виконано регіонарну анестезію під контролем УЗД та нейростимулятора. Обстеження проводилося за допомогою ультразвукового апарату Zonare One 3 використанням високочастотного лінійного датчика. Використовувався нейростимулятор Stimuplex HNS 12 (BBraun). Як місцевий анестетик використовували $0,5 \%$ розчин бупівакаїну.

Результати досліджень та їх обговорення. Пацієнтам проводилася аксилярна блокада плечового сплетіння. Ефективність знеболення визначали по цифровій рейтинговій шкалі, від 1 до 10. В 13 пацієнтів оцінка була «0» до 7 годин після проведення блокади. Застосування ультразвуку дає змогу візуалізувати анатомічні структури навіть при їх нетиповому розташуванні, а також підвести голку до цих структур під безпосереднім контролем зору. Це значно прискорює виконання маніпуляції і зменшує ризики неефективного блоку.

Висновки. Поєднання ультразвукової візуалізації та нейростимуляціії для проведення блокади нервів плечового сплетіння із аксилярного доступа дає можливість отримати достатній рівень анестезії та знизити ризик ненавмисної пункції судин у всіх випадках.

Ключові слова: регіонарна анестезія, плечове сплетіння, ультразвукова діагностика, нейростимулятор.

Axillary block of brachial plexus under simultaneous control of ultrasound and neurostimulator M.M. Ivachevskiy

Uzhhorod National University, Faculty of Medicine, Department of Oncology, Andriy Novak Transcarpathian Regional Clinical Hospital, Uzhhorod

\section{Abstract}

Introduction. The article presents the results of a combination of ultrasound diagnostics and neurostimulationof axillary blockade in patients undergoing surgery on the upper extremity.

Purpose. Introduction of axillary block of the brachialplexus under the simultaneous control of ultrasound and neurostimulatorto the clinical practice.

Materials and methods: The study included 15 patients undergoing regional anesthesia under ultrasound and neurostimulator control. The examination was performed using a Zonare One ultrasound device using a high-frequency linear sensor. Stimuplex HNS 12 (BBraun) neurostimulator was used. As a local anesthetic used a $0.5 \%$ solution of bupivacaine.

Results of the study and discussion. Patients underwent axillary block of the brachial plexus. Efectiveness ofanesthesia was determined on a digital rating scale, from 1 to 10 . In 13 patients, the score was " 0 " until 7 hours after the block. The use of ultrasound makes it possible to visualize anatomical structures even at their atypical location, and to bring the needle to these structures under direct vision control. This greatly speeds up the manipulation and reduces the risk of an inefficient block.

Conclusion. The combination of ultrasound imaging and neurostimulation to block the nerves of the brachial plexus from axillary access allows one to obtain a sufficient level of anesthesia and reduce the risk of unintended vascular puncture in all cases.

Key words: regional anesthesia, brachial plexus, ultrasound, neurostimulator.

Вступ. Останнім часом проведення периферичних регіонарних блокад під контролем ультразвуку знаходить все більше застосування в анестезіологічній практиці. Це пов'язано з тим, що є можливість безпосередньо візуалізувати нерви, контролювати ступінь їх зрошування місцевим анестетиком, цим самим знизити дозу препарата та кількість ускладнень.

Першу публікацію про можливість УЗД периферичних нервів видав Форнадже в 1988 р. [1].
У 1994 році Капрал опублікував першу роботу про використання прямої ультразвукової візуалізації в регіонарній анестезії (надключична блокада плечового сплетіння)[2]. Помилкове внутрішньовенне введення призводить до небажаної системної дії анестетика, умовним ускладненням можна вважати i неефективну блокаду, де частота невдач при виконанні регіонарної анестезії коливається від 0,46 до 35,0\% $[3,4]$. 
Є актуальним застосування регіонарних методик при операціях на верхніх кінцівках, але успіх проведення блокади плечового сплетіння залежить не тільки від досвіду лікаря та знання ним топографічної анатомії, але і від візуалізації нервових сплетінь [5].

Мета дослідження. Впровадження в клінічну практикуаксилярної блокади плечового сплетіння під одночасним контролем ультразвуку та нейростимулятора.

Матеріали та методи. Згідно 3 поставленою метою до дослідження було включено 15 пацієнтів, яким виконано регіонарну анестезію під контролем УЗД та нейростимулятора, при планових оперативних втручаннях на верхній кінцівці (лікоть, передпліччя та кисть) на базі ЗОКЛ ім. А.Новака.

Середній вік пацієнтів становив 57,6 року (від 42 до 78 років).

Критеріями включення були:

- інформована згода пацієнта на проведення блокади;
- оперативне втручання на лікті, передпліччі та кисті.

Критеріями виключення з дослідження була відмова пацієнта від проведення блокади.

Обстеження проводилося за допомоги ультразвукового апарату Zonare One 3 використанням високочастотного лінійного датчика. Використовувався нейростимулятор Stimuplex HNS 12 (BBraun) в режимі SENSe, силою струму 1 мА. Спеціальні одноразові набори для регіонарної анестезіï: Stimuplex® A 22 Gx 2" 0,70 х 50 мм (ізольована голка для провідникової анестезії, електричний імпульс поступає тільки від кінчика, на голці $є$ спеціальний порт для одночасного введення місцевого анестетика). Як місцевий анестетик використовували $0,5 \%$ розчин бупівакаїну.

Для визначення переваги використаної методики блокади плечового сплетіння проводилося оцінювання ефективності знеболення по цифровій рейтинговій шкалі (NPIS)) (рис. 1), кількість випадків переходу на інший вид анестезії, кількість ненавмисних пункцій судин.

\section{0-10 Numeric Pain Intensity Scale ${ }^{\star}$}

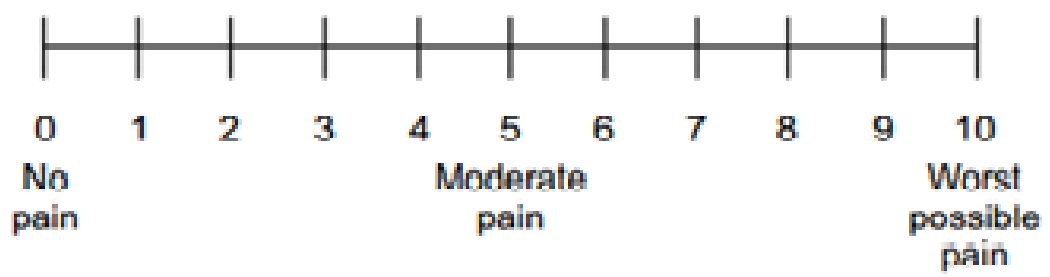

Рис. 1. Цифрова шкала болю

Результати досліджень та їх обговорення. Усім пацієнтам проводилася аксилярна блокада плечового сплетіння. Напередодні блокади пацієнтам проводилось ультразвукове обстеження аксилярної ділянки, з метою вивчення анатомічних особливостей пацієнтів, ідентифікація аксилярної артерії (рис. 1), клювовидно-плечовий, дво- та триголовий м'язи. При проведенні perioнарної анестезії спершу потрібно знайти та ідентифікувати нерв чи нервове сплетіння, далі ін'єкція і створення депо місцевого анестетика навколо відповідних нервів. Положення пацієнта на спині, рука відведена на 90 градусів. Процедура проводилася в асептичних умовах, з використанням стерильного чохла на датчик апарату УЗД, та під м/а. Положення ультразвукового датчика паралельно плечовій складці. Початкова глибина обстеження 2,5-3 см, через те, що аксилярні нерви досить дрібні. Особливо важливим $\epsilon$ ідентифікація артерії (пульсує) і вени (при незначному натискуванні вона спадається). Вводимо голку в краніально-каудальному напрямку по відношенню до датчика in-plane (в площині) (рис. 2). Навколо аксилярної артерії знаходяться три нерви, а саме: серединний (на 9,11 годині), радіальний (на 4,6 годині) та ліктьовий (на 1,3 годин). За допомогою стимуляційної голки ідентифікуємо кожен нерв окремо, достовірність близького розташування кінчика голки біля нерва $\epsilon$ отримання моторної відповіді при силі струму від 0,4 до 0,2 $\mathrm{mA}$ : серединний нерв згинання зап'ястя та пальців, ліктьовий нерв ульнарна девіація зап'ястя, приведення великого пальця, променевий нерв - розгинання зап'ястя та відведення великого пальця, м'язово-шкірний нерв знаходиться дещо нижче, між двоголовим та клювовидно-плечовим м'язом, рухова відповідь - скорочення двоголового м'яза. 


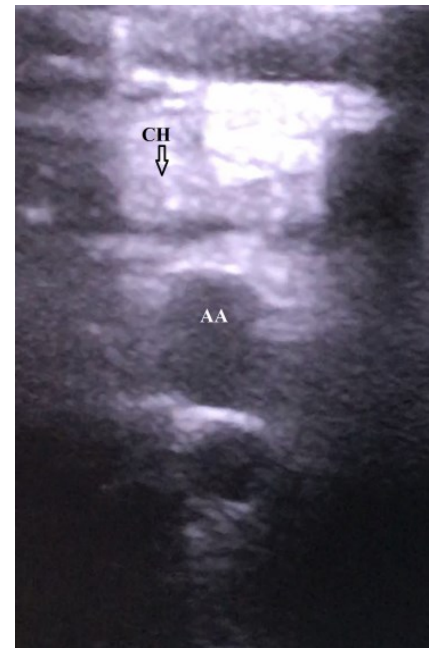

Рис. 1. УЗД аксилярної ділянки: СН-серединний нерв, $\mathrm{AA} \mathrm{-} \mathrm{аксилярна} \mathrm{артерія}$

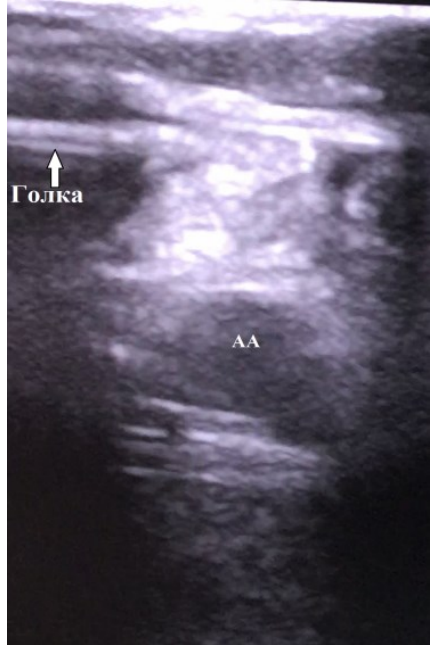

Рис. 2. УЗД аксилярної ділянки з ідентифікацією голки

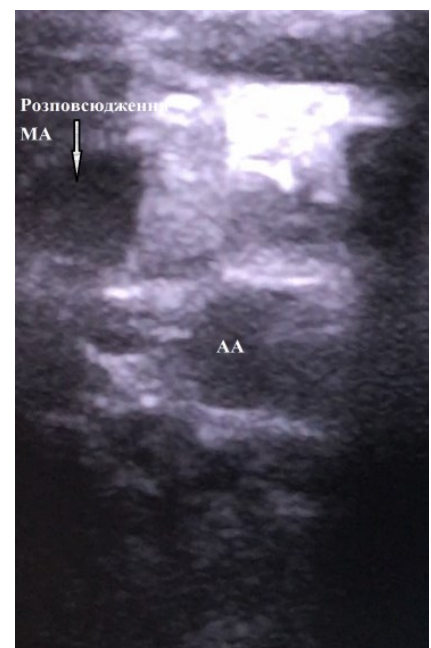

Рис. 3. УЗД аксилярної ділянки: АА - аксилярна артерія, МА-місцевий анестетик
Після ідентифікації нерва навколо нього вводили 5 мл місцевого анестетика (рис. 3), м'язово-шкірний нерв 3 мл, не втрачаючи візуального контролю над кінчиком голки, 3 періодичними аспіраційними пробами, 3 метою запобігання внутрішньо судинного введення місцевого анестетика. Після закінчення процедури ставили асептичну пов'язку.

Із 15 пацієнтів, яким проводилась аксилярна блокада, тільки 2-м було потрібно додаткове проведення загальної анестезії через розширення зони оперативного втручання.

Ефективність знеболення визначали по цифровій рейтинговій шкалі (NPIS), від 1 до 10. У 13 пацієнтів оцінка була «0» до 7 годин після проведення блокади (рис. 6).

Анестезія після блокади розвивалася через 2530 хв, тривалість аналгезії була 9,5 години.

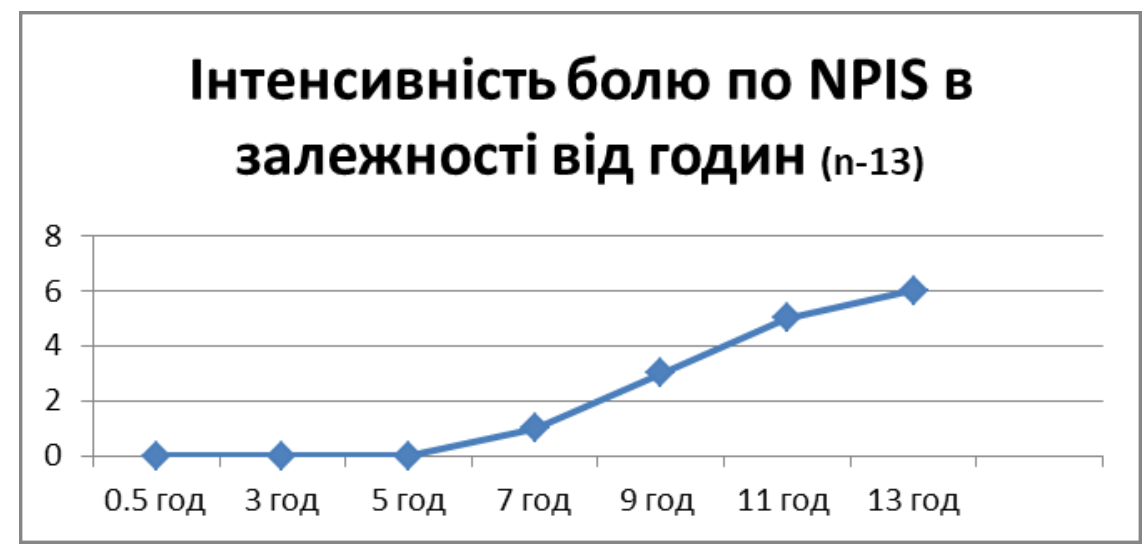

Рис. 4. Результати оцінювання пацієнтів по NPIS.

Під час проведення блокади у 15 пацієнтів не було жодної випадкової пункції судин та не спостерігалося постпункційних гематом.

Пошук сплетіння «по парестезії» поступається сучасним методам ідентифікації: за допомогою електролокації - 3 використанням нейростимулятора або під контролем ультразвукового дослідження, а дискусія з приводу порівняння ефективності цих методик не припиняється [6,7].

Застосування ультразвуку дає змогу візуалізувати анатомічні структури навіть при їх нетиповому розташуванні, а також підвести голку до цих структур під безпосереднім контролем зору. Це значно прискорює виконання маніпуляції і зменшує ризики неефективного блоку. В залежності від того, чи голка проходить в площині ультразвукового променя або виходить із нього, є два типи введення голок: в площині in-plane та поза площиною outofplane, i перший вважається більш безпечним, через те що голка находиться під постійним контролем. Слід зазначити, що в умовах змінених тканин (набряк, гематома) якість візуалізації при ультразвуковому дослідженні також значимо погіршується, тому використання ультразвуку не виключає застосування нейростимулятора у даної категорії пацієнтів [8,9].

Незважаючи на зростаючий інтерес до використання ультразвукової діагностики при виконанні регіонарної анестезії, наприклад, периферичних блокад, все ще існує суперечка щодо 
того, наскільки УЗД перевершує раніше розроблені методи локалізації нерва, такі як використання нейростимулятора. Це в першу чергу пов'язано з низькою ехогенністю більшості видів голок [10].

Деякі анестезіологи пропонують комбінувати нейростимуляцію $з$ ультразвуком, але вона не $\epsilon$ загально прийнятою, оскільки вона робить регіонарну анестезію більш складною [9].

Висновки. Поєднання ультразвукової візуалізації та нейростимуляціїі для проведення блокади нервів плечового сплетіння із аксилярного доступа дає можливість отримати достатній рівень анестезії та знизити ризик ненавмисної пункції судин у всіх випадках.

Інформація про конфлікт інтересів: автори заявляють про відсутність конфлікту інтересів при виконанні наукового дослідження та підготовці даної статті.

Інформація про фінансування: автори гарантують, що вони не отримували жодних винагород у будь-якій формі, здатних вплинути на результати роботи.

\section{Список використаної літератури}

1. Fornage BD. Peripheral nervesof the extremity: imaging with ultrasound. Radiology. 1988 Apr;167(1):17982.

2. Kapral S, Krafft P, Eibenberger K, Fitzgerald R, Gosch M, Weinstabl C. Ultrasoundguided supraclavicular approach for regional anesthesia of the brachial plexus. AnesthAnalg. 1994 Mar;78(3):507-13.

3. KhvysiukO.M., Fesenko V.S, Zavelia M. I. Khvysiuk.Anesteziia v ortopediitatravmatolohii : navch. posyb. Kh. : Prapor, 2006. - 416 s. - Bibliohr.: s. 416 [In Ukrainian].

4. AuroyY, BenhamouD, BarguesL, EcoffeyC, FalissardB, MercierFJ, etal. Major complications of regional anesthesia in France: The SOS Regional Anesthesia Hotline Service. Anesthesiology. 2002 Nov;97(5):1274-80.

5. Man'kov A.V., Gorbachev V.I. Nejroaksial'nye metody obezbolivanija v hirurgii: posobiedljavrachej. Irkutsk, 2010. - 56

6. Sauter AR, Dodgson MS, Stubhaug A, Halstensen AM, Klaastad Ø. Electrical nerve stimulation or ultrasound guidance for lateral sagittal infraclavicular blocks: a randomized, controlled, observer-blinded, comparative study.AnesthAnalg. 2008 Jun;106(6):1910-5. doi: 10.1213/ane.0b013e318173280f.

7. Gürkan Y, Acar S, Solak M, Toker K. Comparison of nerve stimulation vs. ultrasound-guided lateral sagittal infraclavicular block. ActaAnaesthesiol Scand. 2008 Jul;52(6):851-5. doi: 10.1111/j.1399-6576.2008.01655.x. Epub 2008 May 12.

8. Herring AA, Stone MB, Frenkel O, Chipman A, Nagdev AD. The ultrasound-guided superficial cervical plexus block for anesthesia and analgesia in emergency care settings. Am J Emerg Med. 2012 Sep;30(7):1263-7. doi: 10.1016/j.ajem.2011.06.023. Epub 2011 Oct 24.

9. Duger C, Isbir AC, Kaygusuz K, OzdemirKol I, Gursoy S, Ozturk H. The Importance of Needle Echogenity in Ultrasound Guided Axillary Brachial Plexus Block: A Randomized Controlled Clinical Study. Int J Med Sci. 2013 Jul 4;10(9):1108-12. doi: 10.7150/ijms.6598. Print 2013.

10. Abrahams MS, Aziz MF, Fu RF, Horn JL. Ultrasound guidance compared with electrical neurostimulation for peripheral nerve block: a systematic review and meta-analysis of randomized controlled trials. Br J Anaesth. 2009 Mar;102(3):408-17. doi: 10.1093/bja/aen384. Epub 2009 Jan 26.

Стаття надійшла до редакції: 1.02 .2019 р. 